\title{
Effects of sustained subculture on apparent rejuvenation of the apple rootstock M.9 in vitro and in vivo
}

\author{
C.A. Webster and O.P. Jones
}

Institute of Horticultural Research, East Malling, Maidstone, Kent, U.K.

\section{Introduction}

Sequential subculture of fruit trees leads to a gradual physiological change which may be termed 'rejuvenation'. This change is characterized by a gradual improvement in shoot production and rooting in vitro (Jones, 1985).

Hedges established from micropropagated plants of the plum rootstock Pixy (Prunus insititia) continued for at least $9 \mathrm{yr}$ to produce shoot cuttings with the juvenile character of more rapid rooting (Howard et al., 1989a). Thus, rejuvenation as a result of micropropagation may be exploited to improve conventional propagation of clones which are normally difficult to propagate.

This paper describes the apparent rejuvenation in vitro of the apple rootstock M.9 and the subsequent retention of juvenile characters in micropropagated plants in the field. M.9 is one of the most frequently used apple rootstocks worldwide but suffers from the serious shortcoming of being difficult to propagate.

\section{Materials and Methods}

Two shoot culture lines, $A$ and $B$, were established in 1986 from 2 shoot tip explants on MS proliferation medium containing $2 \mathrm{mg} / \mathrm{l}$ BAP (benzylaminopurine), $0.1 \mathrm{mg} / \mathrm{IBA}$ (indole butyric acid) and $162 \mathrm{mg} / \mathrm{l}$ phloroglucinol (PG). These 2 culture lines were subcultured monthly for 21 mo along with 2 other culture lines initiated in 1978 and 1982, respectively. In vitro rooting involved transfer for $4 \mathrm{~d}$ of single shoots from proliferation medium to MS medium containing $3 \mathrm{mg} / \mathrm{IBA}$, followed by transfer for 3 wk to half-strength MS medium without growth regulators. Direct rooting involved transfer of single shoots from proliferation medium, dipped in a powder preparation of $0.2 \%$ IBA $+10 \%$ Captan, to sterile horticultural sand for 4 wk (Webster and Jones, 1989).

Micropropagated plants produced in 1985 from culture lines initiated in 1978 and 1982 were grown in the glasshouse during 1986 and transferred to the field in 1987 as hedge plants.

Rooting of leafy summer cuttings and leafless winter cuttings from these micropropagated plants was evaluated during 1986-1988 in comparison with cuttings from conventionally propagated plants.

\section{Results}

Apparent rejuvenation in vitro

Shoot production with the two 1986 culture lines increased from a mean of 1 new shoot per single shoot inoculum to around 
5 new shoots with monthly subculture over $21 \mathrm{mo}$. Shoot production of culture line B remained significantly higher $(P<0.001)$ than that of culture line $A$. Mean shoot production was greatest at 7 new shoots per inoculum with the 5 and 9 yr old culture lines but there was no significant difference between them.

In vitro rooting of the two 1986 culture lines increased from a mean of $12 \pm 7.8 \%$ after 5 mo on proliferation medium to a maximum of $73 \pm 8.1 \%$ after 12 mo. Rooting of culture line $B$ was significantly higher $(P<0.01)$ than that of line $A$ with a maximum of $93 \pm 6.4 \%$ rooted shoots achieved by culture line B but only $69 \pm$ $11.6 \%$ achieved by culture line $A$. Rooting was consistently high at around $90 \%$ with the 1982 and 1978 culture lines, but there was no significant difference between them.

The presence of phloroglucinol in the proliferation medium improved subsequent rooting at the 11th and 15th subcultures but not at the 21 st subculture.

Establishment of plantlets in compost was low following in vitro rooting but was increased significantly $(P<0.001)$ when shoots from proliferation medium were rooted directly into sand.

\section{Apparent rejuvenation in vivo}

When micropropagated plants from 1978 and 1982 culture lines were grown as field hedges, they produced more than twice as many shoots in the first year as conventional hedges from rooted stoolbed shoots.

Rooting was consistently greater in summer and winter cuttings from micropropagated plants than in cuttings from conventional hedges. In summer 1988, rooting from the micropropagated plants was further improved by severely pruning the stock plants to give the maximum of
$57 \pm 8.9 \%$ in the 1978 source over a 4 wk period as compared with $3 \pm 3.3 \%$ from the severely pruned conventional source.

\section{Discussion and Conclusions}

Monthly subculture of M.9 appeared to induce 'rejuvenation' which was expressed as improved shoot production and rooting in vitro and subsequently of micropropagated plants in the field. Similar increased rooting ability of cuttings from micropropagated stockplants of the plum rootstock Pixy has been sustained for at least $9 \mathrm{yr}$ (Howard et al., 1989a). Differences in shoot production and rooting of M.9 in vitro also appeared to originate from differences between explants used to initiate culture lines.

Decreasing dependence with subculture on phloroglucinol (PG) for rooting suggests that phenolic metabolism may be involved in rejuvenation. This view is also supported by the observation that $P G$ in the culture medium improved poor in vitro growth of shoot tip explants for conventional plants of the plum rootstock Pixy, but had no effect on explants from putatively rejuvenated micropropagated plants (Howard et al., 1989b).

\section{Acknowledgments}

We wish to thank the Agricultural Genetics Company for contributing to the funding of this work.

\section{References}

Howard B.H., Jones O.P. \& Vasek J. (1989a) Long-term improvement in the rooting of plum cuttings following apparent rejuvenation. $J$. Hortic. Sci. 64, 147-156 
Howard B.H., Jones O.P. \& Vasek J. (1989b) Growth characteristics of apparently rejuvenated plum shoots. J. Hortic. Sci. 64, 157-162

Jones O.P. (1985) The role of growth regulators in the propagation in vitro of temperate fruit trees. In: Growth Regulators in Horticulture
(Menhenett R., ed.). British Plant Growth Regulator Group Monograph 13, pp. 113-124

Webster C.A. \& Jones O.P. (1989) Micropropagation of the apple rootstock M.9: effect of sustained subculture on apparent rejuvenation in vitro. J. Hortic. Sci. 64, 421-428 